\title{
Performance evaluation of a full-scale ABS resin manufacturing wastewater treatment plant: a case study in Tabriz Petrochemical Complex
}

\author{
Mohammad Shakerkhatibi ${ }^{1 *}$, Mohammad Mosaferi ${ }^{2}$, Khaled Zorufchi Benis ${ }^{3}$, Zahra Akbari ${ }^{4}$ \\ ${ }^{1}$ Associate Professor of Environmental Engineering, Department of Environmental Health Engineering, Tabriz \\ University of Medical Sciences, Tabriz, Iran \\ ${ }^{2}$ Professor of Environmental Health Engineering, Department of Environmental Health Engineering, Tabriz \\ University of Medical Sciences, Tabriz, Iran \\ ${ }^{3} \mathrm{MSc}$ of Chemical Engineering, Faculty of Chemical Engineering, Sahand University of Technology, Tabriz, Iran \\ ${ }^{4} \mathrm{MSc}$ of Environmental Health Engineering, Student Research Committee, Tabriz University of Medical Sciences, \\ Tabriz, Iran
}

\begin{abstract}
Background: The measurement data regarding the influent and effluent of wastewater treatment plant (WWTP) provides a general overview, demonstrating an overall performance of WWTP. Nevertheless, these data do not provide the suitable operational information for the optimization of individual units involved in a WWTP. A full-scale evolution of WWTP was carried out in this study via a reconciled data.

Methods: A full-scale evolution of acrylonitrile, butadiene and styrene (ABS) resin manufacturing WWTP was carried out. Data reconciliation technique was employed to fulfil the mass conservation law and also enhance the accuracy of the flow measurements. Daily average values from long-term measurements by the WWTP library along with the results of four sampling runs, were utilized for data reconciliation with further performance evaluation and characterization of WWTP.

Results: The full-scale evaluation, based on balanced data showed that removal efficiency based on chemical oxygen demand (COD) and biochemical oxygen demand $\left(\mathrm{BOD}_{5}\right)$ through the WWTP were $80 \%$ and $90 \%$, respectively, from which only $28 \%$ of COD and $20 \%$ of $\mathrm{BOD}_{5}$ removal had occurred in biological reactor. In addition, the removal efficiency of styrene and acrylonitrile, throughout the plant, was approximately $90 \%$. Estimation results employing Toxchem model showed that $43 \%$ of acrylonitrile and $85 \%$ of styrene were emitted into the atmosphere above water surfaces.

Conclusion: It can be concluded that the volatilization of styrene and acrylonitrile is the main mechanism for their removal along with corresponded COD elimination from the WWTP. Keywords: Performance evaluation, Acrylonitrile butadiene styrene (ABS), Petrochemical, Toxchem model

Citation: Shakerkhatibi M, Mosaferi M, Zorufchi Benis K, Akbari Z. Performance evaluation of a full-scale ABS resin manufacturing wastewater treatment plant: a case study in Tabriz Petrochemical Complex. Environmental Health Engineering and Management Journal 2016; 3(3): 151-158. doi: 10.15171/EHEM.2016.14
\end{abstract}

Article History:

Received: 13 June 2016

Accepted: 19 July 2016

ePublished: 4 August 2016

\section{Introduction}

Acrylonitrile butadiene styrene (ABS) is an engineering thermoplastic resin, containing styrene, butadiene and acrylonitrile (ACN) monomers. ABS is the most commonly utilized copolymer in industries including appliance, electrical and electronics, consumer goods, construction, and automotive (1-3). In recent years, the demand for ABS resin has increased globally (2). The production capacity of ABS in Iran is 70000 tons per annum. Among this, 35000 tons of ABS is produced in Tabriz Petrochemical Complex (TPC) each year. The emulsion grafting-blend production technology was employed to produce various grades of $\mathrm{ABS}$ resin in TPC. In this production technology, a-methyl styrene (1100 tons per annum), ACN (8300 tons per annum), butadiene and other auxiliary agents were utilized as feeding materials, resulting to a toxic, refractory and complicated liquid effluent. The wastewater from ABS production unit is one of the typical high strength petrochemical wastewaters $(4,5)$. Typical characteristics of effluents from ABS industries are shown in Table 1.

Conventional treatment of high strength ABS wastewater is normally based on biological processes. According to the literature, among the available biological treatment technologies, activated sludge process (ASP) is the most 
Table 1. Typical characteristics of effluent from ABS industries

\begin{tabular}{|c|c|c|c|c|c|c|c|}
\hline \multirow{2}{*}{ Parameter } & \multirow{2}{*}{ Unit } & \multicolumn{6}{|c|}{ References } \\
\hline & & (34) & (40) & (8) & (2) & (41) & (4) \\
\hline $\mathrm{pH}$ & - & $6.8-7.4$ & $6.2-7.5$ & $6.6-7.3$ & $2.6-7.9$ & $2-3.5$ & $2.5 \pm 0.4$ \\
\hline $\mathrm{T}$ & ${ }^{\circ} \mathrm{C}$ & - & $25-35$ & $25-35$ & - & - & - \\
\hline COD & $\mathrm{mg} / \mathrm{L}$ & $4282-6985$ & $2950-4410$ & $2200-4700$ & $1550-8050$ & $1100-1300$ & $1200 \pm 100$ \\
\hline BOD & $\mathrm{mg} / \mathrm{L}$ & $75-3700$ & $1200-1600$ & $800-2400$ & $272-400$ & $400-500$ & $450 \pm 50$ \\
\hline TKN & $\mathrm{mg} / \mathrm{L}$ & $626-949$ & - & $340-670$ & - & $80-100$ & $100 \pm 10$ \\
\hline $\mathrm{ACN}$ & $\mathrm{mg} / \mathrm{L}$ & $185-292$ & - & - & - & - & - \\
\hline
\end{tabular}

common method employed for treating ABS resin manufacturing effluents with high organic loads (6-8). Nevertheless, it is not efficient for the removal of chemical oxygen demand (COD) and nitrogenous compounds such as ACN and cyanides from such wastewater (8). On the contrary, the ASP has two major disadvantages in petrochemical wastewater treatment, including the possibility of emitting volatile organic compounds (VOCs) into the atmosphere, due to the turbulence and aeration and the relatively high suspended solids which remained in the effluent (9).

Generally, the performance of wastewater treatment plants (WWTPs) is evaluated according to the effluent recommendations of the design for disposal. The data resulting from the measurements on the influent and effluent of WWTP provides a general overview, demonstrating an overall performance of the WWTP. Nevertheless, these data do not provide the appropriate operational information for optimizing individual units involved in a WWTP. To solve this problem, full performance evaluation is needed on individual units of a WWTP. This evaluation is required to assess the effluent quality, in order to meet higher treatment requirement and to also know the feasibility of handling higher hydraulic and/or organic loadings. Over the past two decades, several studies have been carried out to evaluate the performance of both municipal and various industrial WWTPs, worldwide (10-17).

In TPC, the wastewater from ABS resin manufacturing unit is pre-treated utilizing ASP as in-plant control system before discharging into the central WWTP, operated as the end-of-pipe treatment system for all TPC wastewater streams. This study aims to evaluate the performance of each operation and process unit involved in a full scale WWTP treating ABS effluents. In this study, long term information collected from the petrochemical central laboratory, accompanied by the data obtained from experimental measurements was utilized as the data base for performance evaluation. To reduce the (random) measurement error, data reconciliation was employed to enhance the accuracy of the measured data.

\section{Methods}

\section{Description of the WWTP}

The case evaluated in this study is a WWTP located in TPC northwest of Iran. It was designed based on an average flow-rate of $800 \mathrm{~m}^{3} / \mathrm{d}$, which consists of three screens $(\mathrm{P} 1)$, a grit chamber (P2), an equalization basin (P3), a fine screen (P4), a dissolved air floatation (DAF) system (P5), a biological extended aeration activated sludge reactor (S1) and a clarifier (S2) (Figure 1). The design and operational parameters of the full-scale WWTP are shown in Table 2.

\section{Analytical methods}

Four sampling runs were conducted on July, August and October, 2014. Twelve-hour composite samples were collected at the inlet and outlet of treatment units. Sludge samples were also collected from returned and waste streams of primary and secondary clarifiers. The grab samples were collected from returned streams. All measurements were carried out during dry weather flow conditions. Dissolved oxygen and temperature were measured in situ utilizing a DO-meter (AQUALYTIC-AL20OXi). Wastewater samples were analysed for TCOD (5220 B), $\mathrm{BOD}_{5}(5210 \mathrm{~B})$, total dissolved solids (TDS) (1030 E), TSS $(2540 \mathrm{E})$, Alkalinity $(2320 \mathrm{~B}), \mathrm{CN}^{-}\left(4500-\mathrm{CN}^{-} \mathrm{N}\right)$, total phosphorus (TP), $\mathrm{PO}_{4}{ }^{3-}(4500-\mathrm{P}-\mathrm{A}), \mathrm{NH}_{4}^{+}\left(4500-\mathrm{NH}_{3} \mathrm{D}\right)$, $\mathrm{NO}_{3}^{-}\left(4500-\mathrm{NO}_{3}^{-} \mathrm{B}\right), \mathrm{NO}_{2}^{-}\left(4500-\mathrm{NO}_{2}{ }^{-} \mathrm{B}\right)$, total kjeldahl nitrogen (TKN) (4500 - $\mathrm{N}_{\text {org }}$ B). Sludge samples were analysed on COD, mixed liquor suspended solids (MLSS) and mixed liquor volatile suspended solids (MLVSS) based on

Table 2. Design parameters of WWTP

\begin{tabular}{lcccc}
\hline WWTP unit & Number & Volume $\left(\mathbf{m}^{3}\right)$ & Depth $(\mathbf{m})$ & HRT (h) \\
\hline Grit chamber (P2) & 1 & 12 & - & 0.37 \\
Equalization basin (P3) & 1 & 508 & 3 & 14.9 \\
DAF (P5) & 1 & 24 & 3 & 0.5 \\
Aeration basin (S1) & 2 & 766 & 2 & 22.5 \\
Clarifier (S2) & 2 & 105 & 2.6 & 3.1 \\
\hline
\end{tabular}

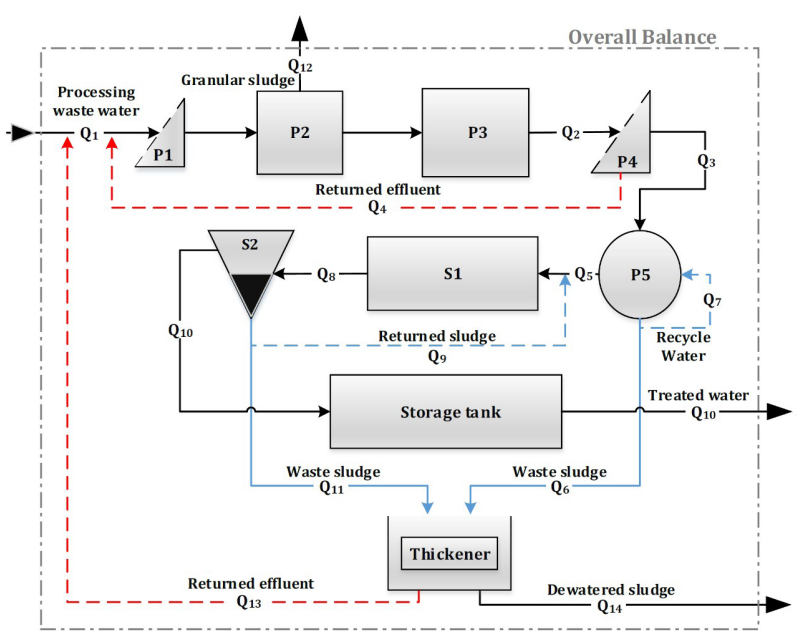

Figure 1. Schematic flow diagram for WWTP. 
the standard methods for the examination of water and wastewater (18).

\section{GC analysis}

The collected samples $(200 \mathrm{~mL})$ from the influent and effluent of treatment units were extracted twice by $50 \mathrm{~mL}$ $\mathrm{CH}_{2} \mathrm{Cl}_{2}$ at the ambient temperature. Thereafter, $50 \mu \mathrm{L}$ of each sample was injected into the GC (Varian Mod CP 3800) equipped with FID detector and a capillary column (CP-WAX $52 \mathrm{CB}: 25 \mathrm{~m} \times 0.32 \mathrm{~mm} \times 1.2 \mu \mathrm{m})$ in order to determine the concentrations of ACN, acrylic acid, acrylamide and styrene. For ACN, acrylic acid and acrylamide analysis, the injector temperature was maintained at $170^{\circ} \mathrm{C}$, while the column was programmed from 40 to $230^{\circ} \mathrm{C}$ at $40^{\circ} \mathrm{C} / \mathrm{min}$ increments ( 3 minutes hold), and the detector was set at $230^{\circ} \mathrm{C}$. For styrene analysis, the temperature was programmed from $40^{\circ} \mathrm{C}\left(1\right.$ minute) to $100^{\circ} \mathrm{C}$ at $20^{\circ} \mathrm{C} / \mathrm{min}$, maintaining this temperature for 1 minute. The detector and injector temperature were set to 300 and $230^{\circ} \mathrm{C}$, respectively.

\section{Data reconciliation}

Measured data from WWTPs often contain gross errors, due to breakdown of the measuring devices, the process dynamics and variability of the influent loading. These errors led to mass imbalance of the WWTP and can also lead to incorrect process design, evaluation and modelling (3). Therefore, operational data should be verified before consideration $(19,20)$. Data reconciliation (DR) is a technique proposed in the early 1950s for reducing the effect of random errors and improving (adjust) the measurement accuracies. This method, based on mass balance, is a well-known and generally used technique for detecting errors within data. The relationship between measurement value, true value and random measurement error can be mathematically written as $(3,21,22)$ :

$y=x+\varepsilon$

Where $y$ is the vector of measurement values (noise free), $x$ is the vector of model values and $\varepsilon$ is the vector of random measurement errors. The aim of DR is to minimize the sum of squares of errors between measurements and model values, subject to a number of constraints (mean balance equations):

$\operatorname{MIN}(y-x)^{T} \psi^{1}(y-x)$

Subject to: $A x=0$

Where, $\psi$ is the weight matrix and $A$ is the process matrix (which is the balance equation).

A constrained optimization problem can be converted into unconstrained optimization problem by means of Lagrange multiplier method. Therefore, the problem can be solved analytically by introducing $\lambda$ as the Lagrange multiplier $(3,23)$ :

$$
L(y, \lambda)=(y-x)^{T} \psi^{-1}(y-x)-2 \lambda^{T} A x
$$

Substituting Equation (1) in Equation (3) gives:

$$
L(y, \lambda)=\varepsilon^{T} \psi^{-1} \varepsilon-2 \lambda^{T}(A y-A \varepsilon)
$$

Considering $\psi$ as the positive definite and the constraints are linear, the necessary and sufficient conditions for minimization are obtained after differentiating Equation (4) with respect to $\varepsilon$ and $\lambda$ and equating them to zero:

$\frac{\partial L}{\partial \varepsilon}=2 \psi^{-1} \varepsilon+2 A^{T} \lambda=0$

$\frac{\partial L}{\partial \lambda}=A(y-\varepsilon)=0$

Which yield Equations (7) and (8):

$$
\begin{aligned}
& \varepsilon=-\psi A^{T} \lambda \\
& \lambda=-\left(A \psi A^{T}\right)^{-1} A y
\end{aligned}
$$

The estimate of the process variable can be obtained as shown in Equation (9):

$$
y_{\text {estimated }}=y-\varepsilon=y-\psi A^{T}\left(A \psi A^{T}\right)^{-1} A y
$$

This method was implemented in MATLAB and applied on measured flow rates.

\section{Results}

Characterization of the influent wastewater

Table 3 presents the influent wastewater characteristics as mean and standard deviation (mean \pm SD). The data shown in Table 3 were calculated utilizing the results of 4 sampling runs and analyses throughout this study as well as comparison to the results of long-term measurements at the WWTP.

According to the data shown in Table 3, flow rate, TCOD, $\mathrm{BOD}_{5}$, TSS, $\mathrm{pH}$ and cyanide are routine parameters which were measured periodically in recent years. Other parameters such as temperature, TKN, ACN and styrene were measured in this study to improve the evaluation of WWTP.

\section{Data reconciliation}

Table 4 shows the mass balance equations in a matrix format. The data shown in Table 4 show the interaction between the different flows and their effect on each com-

Table 3. Characteristics of the raw wastewater

\begin{tabular}{llccc}
\hline \multirow{2}{*}{ Measurements } & Units & $\begin{array}{c}\text { Measured } \\
\text { (this study) }\end{array}$ & $\begin{array}{c}\text { Long-term } \\
\text { data }\end{array}$ & Design \\
\hline $\mathrm{Q}_{\text {ave }}$ & $\mathrm{m}^{3} / \mathrm{d}$ & $469 \pm 57$ & $538 \pm 89$ & 800 \\
$\mathrm{TCOD}$ & $\mathrm{mg} / \mathrm{L}$ & $1345 \pm 414$ & $1377 \pm 653$ & 1200 \\
$\mathrm{BOD}_{5}$ & $\mathrm{mg} / \mathrm{L}$ & $783 \pm 473$ & $647 \pm 248$ & 675 \\
$\mathrm{TSS}$ & $\mathrm{mg} / \mathrm{L}$ & $649 \pm 574$ & $410 \pm 354$ & 300 \\
$\mathrm{pH}$ & - & $6.37 \pm 0.16$ & $6.16 \pm 1.14$ & 3 \\
$\mathrm{Cyanide}$ & $\mathrm{ppb}$ & $105 \pm 31$ & $126 \pm 76$ & - \\
Temperature & ${ }^{\circ} \mathrm{C}$ & $34.5 \pm 2.9$ & - & 67 \\
\hline TKN & $\mathrm{mg} / \mathrm{L}$ & $61 \pm 2$ & - & - \\
Acrylonitrile & $\mathrm{mg} / \mathrm{L}$ & $314 \pm 100$ & - & - \\
Styrene & $\mathrm{mg} / \mathrm{L}$ & $123 \pm 14$ & - & - \\
\hline
\end{tabular}


Table 4. Error diagnosis and data reconciliation of the flow measurements

\begin{tabular}{lllllll}
\hline Streams & \multicolumn{5}{c}{ Subsystem compartments } \\
\cline { 2 - 7 }$\left(\mathbf{m}^{3} / \mathbf{d}\right)$ & $\left.\mathbf{( P}_{1^{\prime}}, \mathbf{P}_{2}, \mathbf{P}_{3}\right)$ & $\mathbf{P}_{4}$ & $\mathbf{P}_{5}$ & $\mathbf{S}_{1}$ & $\mathbf{S}_{2}$ & $\mathbf{T}$ \\
\hline $\mathrm{Q}_{1}$ & 469 & & & & & \\
$\mathrm{Q}_{2}$ & -422 & 422 & & & & \\
$\mathrm{Q}_{3}$ & & -529 & 529 & & & \\
$\mathrm{Q}_{4}$ & 45 & -45 & & & & \\
$\mathrm{Q}_{5}$ & & & -472 & 472 & & \\
$\mathrm{Q}_{6}$ & & & -1 & & & 1 \\
$\mathrm{Q}_{8}$ & & & & -949 & 949 & \\
$\mathrm{Q}_{9}$ & & & & 480 & -480 & \\
$\mathrm{Q}_{10}$ & & & & & -486 & \\
$\mathrm{Q}_{11}$ & & & & & -3 & 3 \\
$\mathrm{Q}_{12}$ & -0.5 & & & & & \\
$\mathrm{Q}_{13}$ & 1.7 & & & & & -1.7 \\
$\mathrm{Q}_{14}$ & & & & & & -2.2 \\
Errors & 93.2 & -152 & 56 & 3 & -20 & 0.1 \\
\hline
\end{tabular}

partment. Using the mass balance matrix as the input of the MATLAB program gives a unique solution and at the same time, increases accuracy of measured data.

Table 5 shows the results of the overall flow balance before and after reconciliation. As shown in Table 5, the measured data contained errors $19.7 \mathrm{~m}^{3} / \mathrm{d}$. Calculation of operational conditions using these unbalanced data, leads to significant error which makes it practically impossible to employ such data for evaluation purposes (14). The standard deviation of balanced data obtained from reconciliation was decreased; and the overall mass balance of WWTP was satisfied.

Performance of individual units of the WWTP

Balanced flow rates were utilized in evaluating the performance of each treatment unit. Figure 2 shows the efficien- cy of individual units of WWTP as the COD and $\mathrm{BOD}_{5}$ removal. In addition, Table 6 illustrates the operating data of the biological reactor.

Figure 3 shows the daily variation of COD in the influent and effluent of WWTP during the study. As shown in Figure 3; in most cases, the effluent concentrations of COD were lower than design criteria $(600 \mathrm{mg} / \mathrm{l})$ across the study period. The effluent characteristics of WWTP are presented in Table 7. Figure 4 shows the fate of styrene, ACN, acrylamide and acrylic acid in WWTP.

\section{Discussion}

In line with the results of this study, the average influent flow rate during the study was significantly lower than design and long-term values. The lower flow rate increases the hydraulic retention time (HRT) in all treatment units except for the biological reactor. Higher HRT values in treatment units and simultaneously high temperature of wastewater along with the turbulence in the tanks, increase potential emissions of VOCs to the atmosphere $(24,25)$.

According to the results, the $\mathrm{COD}$ and $\mathrm{BOD}_{5}$ in the influent were $1345 \pm 414$ and $783 \pm 473 \mathrm{mg} / \mathrm{L}$, respectively, in which both were higher than the WWTP design values. Consequently, the $\mathrm{BOD}_{5} / \mathrm{COD}$ ratio in the influent was calculated as 0.58 which indicates a good potential for biodegradability of the wastewater $(26,27)$. It should be noted that the presence of some toxic and refractory compounds such as cyanide, ACN, etc., in the influent, may adversely affect the performance of biological system $(28,29)$.

The overall COD and $\mathrm{BOD}_{5}$ removal efficiency in WWTP were 80 and $90 \%$, respectively. As can be seen, 52\% (344 $\mathrm{kg} / \mathrm{d})$ removal of COD and $69 \%(266 \mathrm{~kg} / \mathrm{d})$ removal of $\mathrm{BOD}_{5}$ have occurred in preliminary and primary treatment units while; these units are usually designed for

Table 5. Overall mass balance calculations (The positive and negative signs indicate inflows and outflows, respectively)

\begin{tabular}{|c|c|c|c|c|c|}
\hline \multirow{2}{*}{ Streams $\left(\mathrm{m}^{3} / \mathrm{d}\right)$} & \multicolumn{2}{|c|}{ Measured data } & \multicolumn{3}{|c|}{ Balanced data } \\
\hline & Average \pm SD & RSD (\%) & Average \pm SD & RSD (\%) & Estimated error (\%) \\
\hline Influent flow & $469 \pm 57$ & 12.2 & $487 \pm 14$ & 2.9 & 3.7 \\
\hline Effluent flow & $-489 \pm 63$ & 12.9 & $-487 \pm 13$ & 7.4 & -0.42 \\
\hline Treated effluent & $-486 \pm 62$ & 12.8 & $-484 \pm 12$ & 2.5 & -0.41 \\
\hline Waste activated sludge & $-2.2 \pm 0.2$ & 9.1 & $-2.2 \pm 0.2$ & 9.1 & 0 \\
\hline Grit chamber effluent & $-0.5 \pm 0.1$ & 20 & $-0.5 \pm 0.1$ & 20 & 0 \\
\hline Error in measurements & -19.7 & - & 0.00 & & - \\
\hline
\end{tabular}
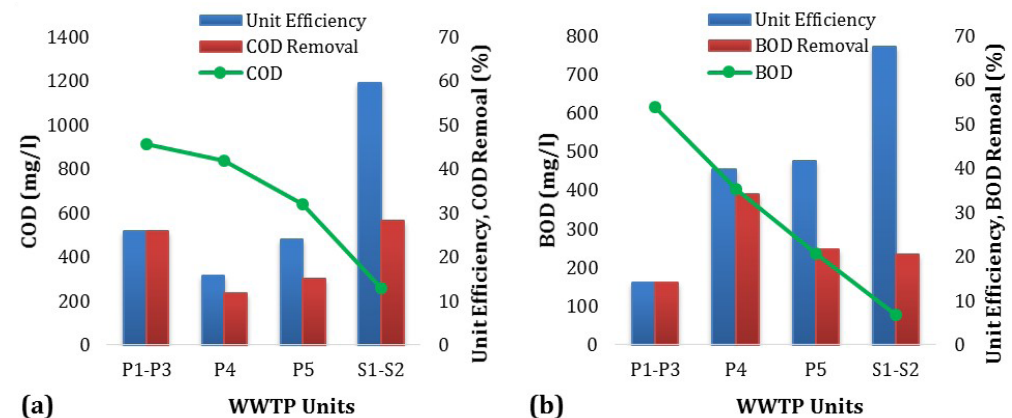

Figure 2. Removal efficiencies of individual units of WWTP as COD and BOD . 
Table 6. Operational characteristics of biological reactor

\begin{tabular}{|c|c|c|c|c|}
\hline Measurements & Units & Design data & Measured data & (26) \\
\hline DO & $\mathrm{mg} / \mathrm{l}$ & - & $3.04 \pm 0.47$ & - \\
\hline $\mathrm{pH}$ & - & $6.5-7.5$ & $7.05 \pm 0.13$ & - \\
\hline Temperature & ${ }^{\circ} \mathrm{C}$ & - & $31.2 \pm 2.8$ & - \\
\hline HRT & $\mathrm{h}$ & 22.5 & 19.4 & $20-30$ \\
\hline SRT & $d$ & - & 21.2 & $20-40$ \\
\hline SVI & $\mathrm{ml} / \mathrm{g}$ & $80-120$ & $277 \pm 42$ & - \\
\hline MLSS & $\mathrm{mg} / \mathrm{L}$ & $2500-3000$ & $1816 \pm 236$ & $2000-5000$ \\
\hline MLVSS & $\mathrm{mg} / \mathrm{L}$ & $1500-1800$ & $1408 \pm 206$ & - \\
\hline $\mathrm{F} / \mathrm{M}$ & kgBOD/kgMLVSS.d & 0.15 & 0.15 & $0.04-0.1$ \\
\hline OLR & $\mathrm{kgBOD} / \mathrm{m}^{3} . \mathrm{d}$ & 0.45 & 0.28 & $0.1-0.3$ \\
\hline RAS & $\%$ of influent & - & 99.1 & $50-150$ \\
\hline
\end{tabular}

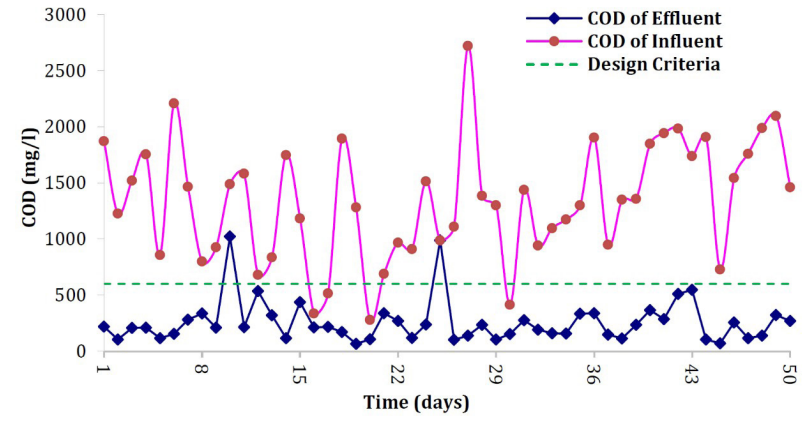

Figure 3. Daily variation of COD in the influent and effluent of WWTP

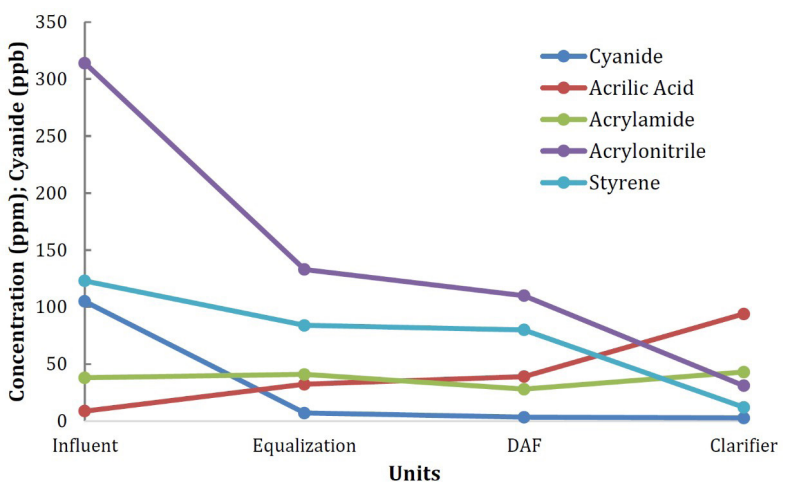

Figure 4. Variations of styrene, acrylonitrile, acrylamide, acrylic acid and cyanide in different units of WWTP.

Table 7. Characteristics of treated effluent

\begin{tabular}{lccc}
\hline Measurements & Units & Design value & Measured data \\
\hline DO & $\mathrm{mg} / \mathrm{l}$ & 2 & $2.1 \pm 1.1$ \\
Temperature & ${ }^{\circ} \mathrm{C}$ & - & $30.3 \pm 1.9$ \\
$\mathrm{COD}$ & $\mathrm{mg} / \mathrm{l}$ & $\leq 600$ & $260 \pm 45$ \\
$\mathrm{BOD}_{5}$ & $\mathrm{mg} / \mathrm{l}$ & $\leq 200$ & $77 \pm 13$ \\
$\mathrm{TSS}$ & $\mathrm{mg} / \mathrm{l}$ & $\leq 50$ & $74 \pm 37$ \\
Acrylonitrile & $\mathrm{mg} / \mathrm{l}$ & - & $31 \pm 4$ \\
Styrene & $\mathrm{mg} / \mathrm{l}$ & - & $12 \pm 2.5$ \\
Cyanide & $\mathrm{ppb}$ & 2 & $2.7 \pm 0.8$ \\
\hline
\end{tabular}

eliminating suspended solids as well as equalizing quantitative and qualitative parameters. Reduction in COD and $\mathrm{BOD}_{5}$ prior to biological unit can be due to the removal of TSS in previous units such as fine screen and DAF and also VOCs stripping of volatile compounds into the atmo- sphere. Since the removal rate of TSS as the main probable separated constituents of COD was fairly small before the aeration basin, it can be concluded that a major portion of COD removal at the upstream units of the biological reactor has probably occurred as a result of VOCs stripping to the atmosphere. It is estimated that about $84 \%$ of total VOCs in a petrochemical wastewater can be released into the atmosphere from the WWTP through stripping process (30). These undesirable emissions can be considered as one of the sources of air pollution, having serious adverse health effects on human $(31,32)$.

Figure 2 shows average $\mathrm{BOD}_{5}$ and COD removal of 68 and $59 \%$, respectively, across the biological reactor at an average organic loading rate (OLR) of $0.236 \mathrm{kgBOD} / \mathrm{m}^{3} . \mathrm{d}$. Generally, the efficiency of biological treatment process severely depends on the reactor design and operational conditions. The operating data of the biological reactor (Table 6) shows that some parameters are out of the range when compared to the WWTP design and literature recommended values.

The mean value of MLSS within the activated sludge was $1816 \pm 236 \mathrm{mg} / \mathrm{L}$, while it should be in the range of 2500 $3000 \mathrm{mg} / \mathrm{L}$ in line with the plant design. Also, the mean value of MLSS measured in returned activated sludge (RAS) was $3410 \pm 564 \mathrm{mg} / \mathrm{L}$. According to literature, the MLSS concentration of RAS from clarifiers should typically be in the range of 4000 to $12000 \mathrm{mg} / \mathrm{L}$ (26). However, the RAS pumping rate was $99.1 \%$ at an average flow rate; the lower values of MLSS in RAS have failed the return stream to maintain a sufficient concentration of activated sludge in the aeration tank to obtain the necessary degree of treatment in the desired time interval. It seems that it can be the cause of insufficient removal rates of $\mathrm{BOD}_{5}$ and COD across the bioreactor. The low values of MLSS have led to the increase of the food to microorganism (F/M) ratio (up to $0.168 \mathrm{kgBOD} / \mathrm{kgMLVSS}$.d) within the bioreactor.

As shown in Table 6, the HRT in aeration tank was 19.4 hours at average flow, while the corresponding design value was 22.5 hours. The reduction in HRT was as a result of the RAS flow rate from clarifier. The decrease in MLSS concentration and HRT in the bioreactor may severely affect the performance of organic compounds oxidation and nitrification processes, which can lead to process un- 
steadiness and poor quality of the effluent.

The results indicated poor removal of TSS in DAF system $(54 \pm 15 \%)$. Also, the COD and $\mathrm{BOD}_{5}$ removal efficiencies in DAF system were $24 \pm 9$ and $42 \pm 6 \%$, respectively, which show variations in the unit's performance over the operating period. Unsteady characteristics of the influent, shows the inadequacy of the chemical additions and the full-influent pressurization in the DAF system which can be considered as the main reasons for the unstable performance of DAF system.

Generally, the WWTP demonstrated sufficient removal efficiency with respect to $\mathrm{COD}, \mathrm{BOD}_{5}, \mathrm{ACN}$ and styrene. Although TSS removal efficiency of the plant was $90 \%$, TSS concentration in effluent was higher than design value which was mainly due to the higher concentration of TSS in the influent and the poor removal performance of screening and DAF.

Nitrile compounds and their derivatives are cyanidesubstituted carboxylic acids that have an $\mathrm{R}-\mathrm{CN}$ structure. Most nitriles are highly toxic and some are mutagenic and carcinogenic. ACN contains a $-\mathrm{CN}$ group which is toxic to organisms and it is not easily decomposed biologically (33). As shown in Figure 4, preliminary treatment units (grit chamber and equalization tank) removed the major portion of ACN (58\%) and cyanide (94\%). The high removal rate in equalization tank may be due to the turbulence effect created by high aeration rate (32).

As shown in Figure 4, the acrylic acid concentration increased and accumulated with the removal of ACN. Wang and Lee (34) indicated that the microorganisms within the biological reactor use ACN as a substrate which leads to the accumulation of acrylic acid in the system. After the complete removal of ACN, the acrylic acid is consumed. Therefore, incomplete removal of ACN in the biological treatment can be as a result of the low HRT. In the case of styrene, $31 \%$ was removed in preliminary treatment units. The styrene removal efficiency of the biological reactor was $85 \%$. As earlier mentioned, the large portion of styrene and $\mathrm{ACN}$ can be emitted into the atmosphere from the surfaces. All of the styrene and ACN removal (90\%) throughout the WWTP are not related to biodegradation or elimination by other effluents such as granular or dewatered sludge.

Toxchem model (Environmega), which was designed to model the fate of toxic organic chemicals in wastewater treatment processes and regarded by USEPA as appropriate models for air emissions estimation (35-37), was employed to estimate the portion of air emission of each component. The results revealed showed that $43 \%$ ( 65 $\mathrm{kg} / \mathrm{d})$ and $85 \%(51 \mathrm{~kg} / \mathrm{d})$ of entered ACN and styrene were emitted into the air, respectively, in which the equalization basin had the major portion of the air emission. The high emission rate from equalization basin is as a result of high concentration of pollutants in the basin and its large surface area for evaporation $(25,38)$. Cheng and Chou (39) indicted that the turbulence effect could result in total VOC emission, increasing from 46 to $90 \%$.

\section{Conclusion}

A full-scale evaluation of the ABS WWTP was conducted in this study. The method of error detection and data reconciliation was employed to correct raw flow rate data and fulfil the mass balance. The evaluation results, using balanced data showed that 52\% (344 kg/d) and 69\% (266 $\mathrm{kg} / \mathrm{d}$ ) loss of COD and $\mathrm{BOD}_{5}$, respectively, occurred in the upstream units of the biological reactor. Nevertheless, removal efficiency of biological reactor was 59 and $68 \%$ for $\mathrm{COD}$ and $\mathrm{BOD}_{5}$, respectively. The results showed inadequate TSS removal of DAF system, which was mainly due to inadequacy of the chemical additions as well as the full-influent pressurization of the system. Investigating the fate of styrene and ACN by means of Toxchem model revealed that a large portion of these were emitted into the atmosphere. The high emission rates from low height area sources can lead to high concentration of considered toxic pollutants in the ambient air around WWTP.

\section{Acknowledgments}

The authors would like to appreciate the help and support provided by Tabriz Petrochemical Company for permitting sampling and also supplying data required.

\section{Ethical issues}

We certify that all data collected during the current study was presented in this manuscript; no data from the study has been or will be published separately. The local ethical review committee of the Tabriz University of Medical Sciences approved the study (Ethical No. B/255).

\section{Competing interests}

The authors declare they have no competing interests.

\section{Authors' contributions}

All authors were involved in study design, data collection, and article approval.

\section{References}

1. Magallon-Cacho L, Perez-Bueno JJ, Meas-Vong Y, Stremsdoerfer G, Espinoza-Beltran FJ. Surface modification of acrylonitrile-butadiene-styrene (ABS) with heterogeneous photocatalysis $\left(\mathrm{TiO}_{2}\right)$ for the substitution of the etching stage in the electroless process. Surf Coat Technol 2011; 206(6): 1410-5. doi: 10.1016/j.surfcoat.2011.09.005.

2. Lai B, Zhou Y, Yang P, Wang K. Comprehensive analysis of the toxic and refractory pollutants in acrylonitrilebutadiene-styrene resin manufacturing wastewater by gas chromatography spectrometry with a mass or flame ionization detector. J Chromatogr A 2012; 1244: 161-7. doi: 10.1016/j.chroma.2012.04.058.

3. Sun Z, Shen Z, Zhang X, Ma S. Co-recycling of acrylonitrilebutadiene-styrene waste plastic and nonmetal particles from waste printed circuit boards to manufacture reproduction composites. Environ Technol 2015; 36(2): 160-8. doi: 0.1080/09593330.2014.940399.

4. Lai B, Zhou Y, Wang J, Zhang Y, Chen Z. Passivation process and the mechanism of packing particles in the $\mathrm{Fe}^{0} / \mathrm{GAC}$ system during the treatment of $\mathrm{ABS}$ resin wastewater. Environ Technol 2014; 35(8): 973-83. doi: 


\subsection{0/09593330.2013.857700}

5. Shakerkhatibi M, Ganjidoust H, Ayati B, Fatehifar E. Performance of aerated submerged fixed-film bioreactor for treatment of acrylonitrile-containing wastewater. J Environ Health Sci Eng 2010; 7(4): 327-36.

6. Azadi NA, Falahzadeh RA, Sadeghi S. Dairy wastewater treatment plant in removal of organic pollution: a case study in Sanandaj, Iran. Environmental Health Engineering and Management Journal. 2015; 2(2): 73-7.

7. Chang CY, Tanong K, Chiemchaisri C, Vigneswaran S. Feasibility study of a cyclic anoxic/aerobic two-stage MBR for treating ABS resin manufacturing wastewater. Bioresource Technol 2011; 102(9): 5325-30. doi: 10.1016/j. biortech.2010.11.116.

8. Chang CY, Tanong K, Xu J, Shon H. Microbial community analysis of an aerobic nitrifying-denitrifying MBR treating ABS resin wastewater. Bioresource Technol 2011; 102(9): 5337-44. doi: 10.1016/j.biortech.2010.12.045.

9. Fallah N, Bonakdarpour B, Nasernejad B, Alavi Moghadam MR. Long-term operation of submerged membrane bioreactor (MBR) for the treatment of synthetic wastewater containing styrene as volatile organic compound (VOC): Effect of hydraulic retention time (HRT). J Hazard Mater 2010; 178(1-3): 718-24. doi: 10.1016/j.jhazmat.2010.02.001.

10. Morales-Mora MA, Paredes JL, Montes deOca JA, Mendoza-Escamilla VX, Martinez-Delgadillo SA. Modeling and performance evaluation of a full scale petrochemical wastewater treatment process. Int J Environ Res 2015; 9(1): 77-84.

11. Yan Q, Gao X, Huang L, Gan XM, Zhang YX, Chen YP, et al. Occurrence and fate of pharmaceutically active compounds in the largest municipal wastewater treatment plant in Southwest China: Mass balance analysis and consumption back-calculated model. Chemosphere 2014; 99: 160-70. doi: 10.1016/j.chemosphere.2013.10.062.

12. Ukpong E. Performance evaluation of activated sludge wastewater treatment plant (ASWTP) At QIT, Ibeno local government area of Akwa Ibom state, Nigeria. Int J Eng Sci 2013; 2(7): 1-13.

13. Naddafi K, Hassanvand M, Dehghanifard E, Razi DF, Mostofi S, Kasaee N, et al. Performance evaluation of wastewater stabilization ponds in Arak-Iran. J Environ Health Sci Eng 2009; 6(1): 41-6.

14. Puig S, Van Loosdrecht MC, Colprim J, Meijer SC. Data evaluation of full-scale wastewater treatment plants by mass balance. Water Res 2008; 42(18): 4645-55. doi: 10.1016/j. watres.2008.08.009.

15. Al Mutairi NZ, Al Sharifi FA, Al Shammari SB. Evaluation study of a slaughterhouse wastewater treatment plant including contact-assisted activated sludge and DAF. Desalination 2008; 225(1-3): 167-75. doi: 10.1016/j. desal.2007.04.094.

16. Del Nery V, De Nardi IR, Damianovic MH, Pozzi E, Amorim AK, Zaiat M. Long-term operating performance of a poultry slaughterhouse wastewater treatment plant. Resour Conserv Recy 2007; 50(1): 102-14. doi: 10.1016/j. resconrec.2006.06.001.

17. Colmenarejo MF, Rubio A, Sánchez E, Vicente J, Garcia MG, Borja R. Evaluation of municipal wastewater treatment plants with different technologies at Las Rozas, Madrid (Spain). J Environ Manag 2006; 81(4): 399-404. doi: 10.1016/j.jenvman.2005.11.007.

18. American Public Health Association (APHA). Standard methods for the examination of water and wastewater. Washington DC: APHA; 2005.

19. Spindler A. Structural redundancy of data from wastewater treatment systems. Determination of individual balance equations. Water Res 2014; 57: 193-201. doi: 10.1016/j. watres.2014.03.042.

20. Meijer SC, Van Der Spoel H, Susanti S, Heijne JJ, Van Loosdrecht MC. Error diagnostics and data reconciliation for activated sludge modelling using mass balances. Water Sci Technol 2002; 45(6): 145-56.

21. Lim J, Sankarrao B, Oh T, Kim M, Kang O, Kim J, et al. Estimation of nitrous oxide emissions (GHG) from wastewater treatment plants using closed-loop mass balance and data reconciliation. Korean J Chem Eng 2012; 29(9): 1123-8. doi: 10.1007/s11814-011-0283-2.

22. Narasimhan $S$, Bhatt $N$. Deconstructing principal component analysis using a data reconciliation perspective. Comput Chem Eng 2015; 77: 74-84. doi: 10.1016/j. compchemeng.2015.03.016.

23. Crowe CM, Garcia Campos YA, Hrymak A. Reconciliation of process flow rates by matrix projection. Part I: linear case. AIChE J 1983; 29(6): 881-8. doi: 10.1002/aic.690290602.

24. Atasoy E, Dogeroglu T, Kara S. The estimation of NMVOC emissions from an urban-scale wastewater treatment plant. Water Res 2004; 38(14-15): 3265-74. doi: 10.1016/j.watres. 2004.04.036.

25. Yang WB, Chen WH, Yuan CS, Yang JC, Zhao QL. Comparative assessments of VOC emission rates and associated health risks from wastewater treatment processes. J Environ Monit 2012; 14(9): 2464-74. doi: $10.1039 / \mathrm{c} 2 \mathrm{em} 30138 \mathrm{e}$.

26. Tchobanoglous G, Burton FL, Stensel HD. Wastewater Engineering: Treatment and Reuse. Boston: McGraw-Hill; 2003.

27. Jafarzadeh Haghighi Fard NA, Jorfi S, Ahmadi M, Mirali S, Kujlu R. Treatment of mature landfill leachate by chemical precipitation and Fenton advanced oxidation process. Environmental Health Engineering and Management Journal 2016; 3(1): 35-40.

28. Na C, Zhang Y, Deng M, Quan X, Chen S, Zhang Y. Evaluation of the detoxication efficiencies for acrylonitrile wastewater treated by a combined anaerobic oxic-aerobic biological fluidized tank (A/O-ABFT) process: acute toxicity and zebrafish embryo toxicity. Chemosphere 2016; 154: 1-7. doi: 10.1016/j.chemosphere.2016.03.037.

29. Van Agteren MH, Keuning S, Oosterhaven J. Handbook on Biodegradation and Biological Treatment of Hazardous Organic Compounds. Netherlands: Springer; 2013.

30. Fatehifar E, Kahforoshan D, Khazini L, Soltanmohammadzadeh J, Sattar H. Estimation of VOC emission from wastewater treatment unit in a petrochemical plant using emission factors. WSEAS Conferences; Santander, Spain; 2008.

31. Mo Z, Shao M, Lu S, Qu H, Zhou M, Sun J, et al. Processspecific emission characteristics of volatile organic compounds (VOCs) from petrochemical facilities in the Yangtze River Delta, China. Sci Total Environ 2015; 533: 422-31. doi: 10.1016/j.scitotenv.2015.06.089.

32. Cheng WH, Hsu SK, Chou MS. Volatile organic compound emissions from wastewater treatment plants in Taiwan: Legal regulations and costs of control. J Environ Manag 2008; 88(4): 1485-94. doi: 10.1016/j.jenvman.2007.07.022.

33. Wang CC, Lee CM, Chen LJ. Removal of nitriles from synthetic wastewater by acrylonitrile utilizing bacteria. J 
Environ Sci Health A 2004; 39(7): 1767-79.

34. Wang CC, Lee CM. Denitrification with acrylamide by pure culture of bacteria isolated from acrylonitrile-butadienestyrene resin manufactured wastewater treatment system. Chemosphere 2001; 44(5): 1047-53.

35. Santos JM, Kreim V, Guillot JM, Reis NC Jr, De Sa LM, Horan NJ. An experimental determination of the $\mathrm{H}_{2} \mathrm{~S}$ overall mass transfer coefficient from quiescent surfaces at wastewater treatment plants. Atmos Environ 2012; 60: 1824. doi: 10.1016/j.atmosenv.2012.06.014

36. Zhang K. Characterization and uncertainty analysis of VOCs emissions from industrial wastewater treatment plants. Environ Prog Sustain Energy 2010; 29(3): 265-71. doi: 10.1002/ep.10377.

37. Kemp J, Zylner RG, Sterne L, Rittmann BE. Measuring and modelling VOC biotransformation rates. Environ Technol 2002; 23(5): 547-51. doi: 10.1080/09593332308618389.
38. Yang J, Wang K, Zhao Q, Huang L, Yuan CS, Chen WH, et al. Underestimated public health risks caused by overestimated VOC removal in wastewater treatment processes. Env Sci Process Im 2014; 16(2): 271-9. doi: 10.1039/c3em00487b.

39. Cheng WH, Chou MS. VOC emission characteristics of petrochemical wastewater treatment facilities in southern Taiwan. J Environ Sci Heal A 2003; 38(11): 2521-35.

40. Chang CY, Chang JS, Lin YW, Erdei L, Vigneswaran S. Quantification of air stripping and biodegradation of organic removal in acrylonitrile-butadiene-styrene (ABS) industry wastewater during submerged membrane bioreactor operation. Desalination 2006; 191(1-3): 162-8. doi: $\quad 10.1016 /$ j.desal.2005.08.014.

41. Lai B, Zhou Y, Yang P. Treatment of wastewater from acrylonitrile-butadiene-styrene (ABS) resin manufacturing by $\mathrm{Fe}^{0} / \mathrm{GAC}-\mathrm{ABFB}$. Chem Eng J 2012; 200-202: 10-7. doi: 10.1016/j.cej.2012.06.030. 